\title{
Epstein-Barr virus-associated iris smooth muscle tumor with epithelioid morphology in AIDS patients: a case report
}

This article was published in the following Dove Press journal:

International Medical Case Reports Journal

30 March 2016

Number of times this article has been viewed

\author{
Yanin Suwan' \\ Duangnate Rojanaporn' \\ Chaiwat Teekhasaenee' \\ Somboon Keelawat ${ }^{2}$ \\ 'Department of Ophthalmology, \\ Faculty of Medicine, Ramathibodi \\ Hospital, Mahidol University, \\ ${ }^{2}$ Department of Pathology, Faculty \\ of Medicine, King Chulalongkorn \\ Memorial Hospital, Chulalongkorn \\ University, Bangkok, Thailand
}

Importance: Report of an acquired immunodeficiency syndrome (AIDS) patient with Epstein-Barr virus (EBV)-associated iris smooth muscle tumor.

Observations: A 14-year-old African American female diagnosed with AIDS developed a painless iris mass in the right eye for 10 months. Iridocyclectomy was performed, and the pathology indicated EBV-associated iris smooth muscle tumor with epithelioid morphology. Immunohistochemical stains and in situ hybridization for EBV-encoded ribonucleic acid are very useful diagnostic tools for definite diagnosis. At 14-month follow-up, the patient did not have any tumor recurrence.

Conclusion: This is the case report of EBV-associated iris smooth muscle tumor in a person diagnosed with AIDS with a unique epithelioid morphologic feature.

Keywords: human immunodeficiency virus (HIV), acquired immunodeficiency syndrome (AIDS), iris tumor, Epstein-Barr virus, smooth muscle tumor, leiomyosarcoma

\section{Introduction}

Acquired immunodeficiency syndrome (AIDS) patients have an increased susceptibility to develop multiple malignant neoplasms. One of the well-recognized lesion in AIDS is Epstein-Barr virus (EBV)-induced smooth muscle tumor (SMT). ${ }^{1}$ They can occur in several anatomic sites. However, uveal tract EBV-associated SMTs are extremely rare, to the best of knowledge only seven cases have been described in the English literature..$^{2-8}$ This report describes another documented AIDS patient with EBV-associated iris SMT, which is unique for its prominent epithelioid morphology.

\section{Methods}

A case of EBV-associated iris SMT was diagnosed and followed up in Ramathibodi Hospital, a tertiary referral center, between May 2014 and June 2014.

\section{Case report}

A 14-year-old African American female developed a painless iris mass in the right eye for 10 months. She had a vertically transmitted human immunodeficiency virus (HIV) infection since birth. As a result of poor compliance, the most recent CD4 count was 27 cell $/ \mathrm{mm}^{3}$ without previous opportunistic infections. HIV viral load was 60,261 copies $/ \mathrm{mL}$. The patient had been taking antiretroviral drugs (nevirapine, zidovudine, and lamivudine) and trimethoprim/sulfamethoxazole at the time of visit.

She complained of blurred vision in the right eye. Her best-corrected visual acuity was 20/70 OD and 20/25 OS. Slit-lamp biomicroscopy in the right eye revealed an
Department of Ophthalmology, Faculty of Medicine, Ramathibodi Hospital, Mahidol University, Bangkok, Thailand

Tel +6622012729

Fax +66 23547280

Email yanin.suwan@gmail.com 


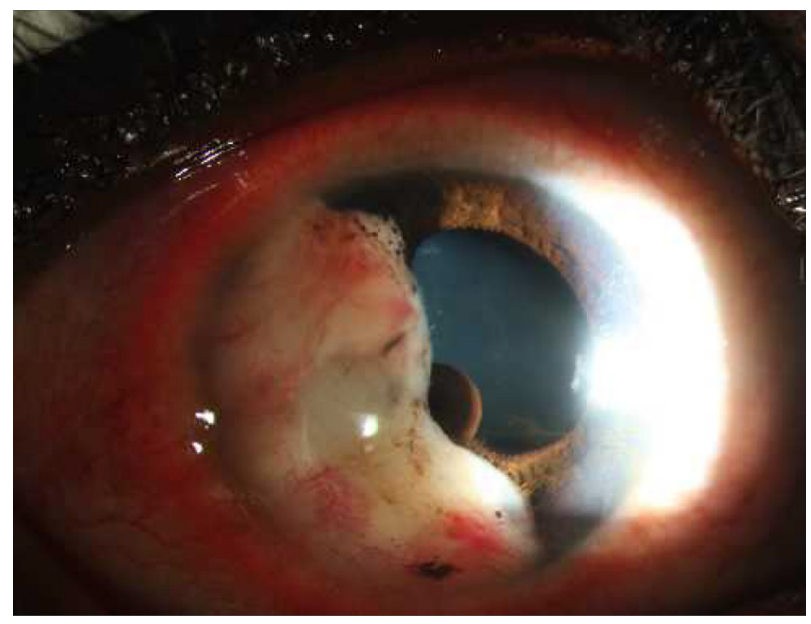

Figure I A well-circumscribed amelanotic iris mass with underlying multiple posterior pigment epithelial cysts.

oval, yellowish, highly vascularized iris mass with $6 \mathrm{~mm}$ horizontal diameter and $10 \mathrm{~mm}$ vertical diameter extending from the 4:00 to 11:00 positions (Figure 1). Multiple iris pigment epithelial cysts were found adhering to the posterior iris surface. Slit-lamp biomicroscopy of the left eye and dilated ophthalmoscopies of both eyes demonstrated no significant findings. Gonioscopy showed a tumor occupying the entire iris surface and obstructing the temporal anterior chamber angle. The anterior surface of the tumor adhered to the corneal endothelium. Ultrasound biomicroscopy revealed a hypoechoic mass coalesced with iris stroma and multiple underlying posterior iris pigment epithelial cysts (Figure 2). The largest diameter was 5.6 (horizontal) and $9.3 \mathrm{~mm}$ (vertical) by ultrasonic measurements. Since the tumor was confined within the iris tissue with ciliary body extension, an iridocyclectomy was performed to remove the entire mass. The neoplastic lesion that was removed was solid with homogeneous gray-white cut surfaces.

Histology revealed the specimen consisting of iris tissue with an attached tumor mass. The tumor lesion consisted of

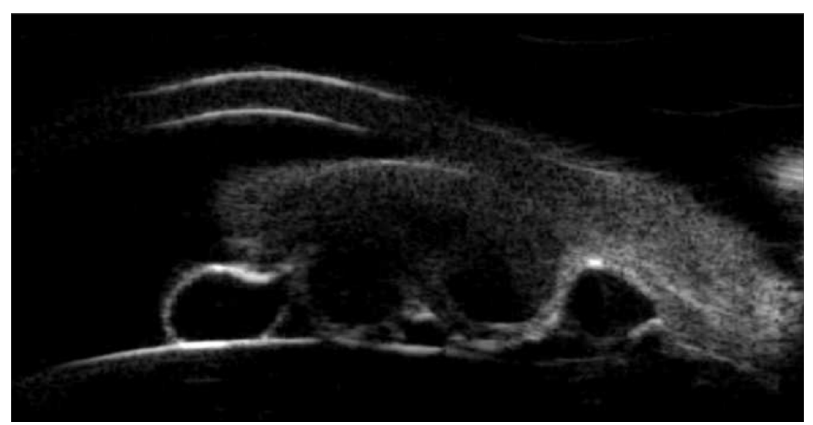

Figure 2 UBM revealed a hypoechoic mass coalesced with iris stroma with $5.6 \mathrm{~mm}$ horizontal diameter and $9.3 \mathrm{~mm}$ vertical diameter. Abbreviation: UBM, ultrasound biomicroscopy. plump-shaped and epithelioid-appearing cells containing mildly pleomorphic, vesicular nuclei with inconspicuous nucleoli, and ill-defined eosinophilic cytoplasm. Vague fascicular arranging pattern was observed. Mitotic count was $\sim 8 / 10$ high-power fields (HPF). Tumor necrosis was not found. Because of its epithelioid shape, tumors with such morphology, eg, malignant melanoma, undifferentiated carcinoma, and EBV-SMT were included in the lists of differential diagnoses with immunohistochemical studies which were performed accordingly. The neoplastic cells were strongly reactive to smooth muscle actin but negative to cytokeratin (AE1/AE3), S-100, desmin, epithelial membrane antigen, and HMB-45. In situ hybridization for EBV-encoded ribonucleic acid revealed a positive reaction in most regions of the tumor (Figure 3). The final diagnosis was, therefore, concluded as "EBV-associated SMT".

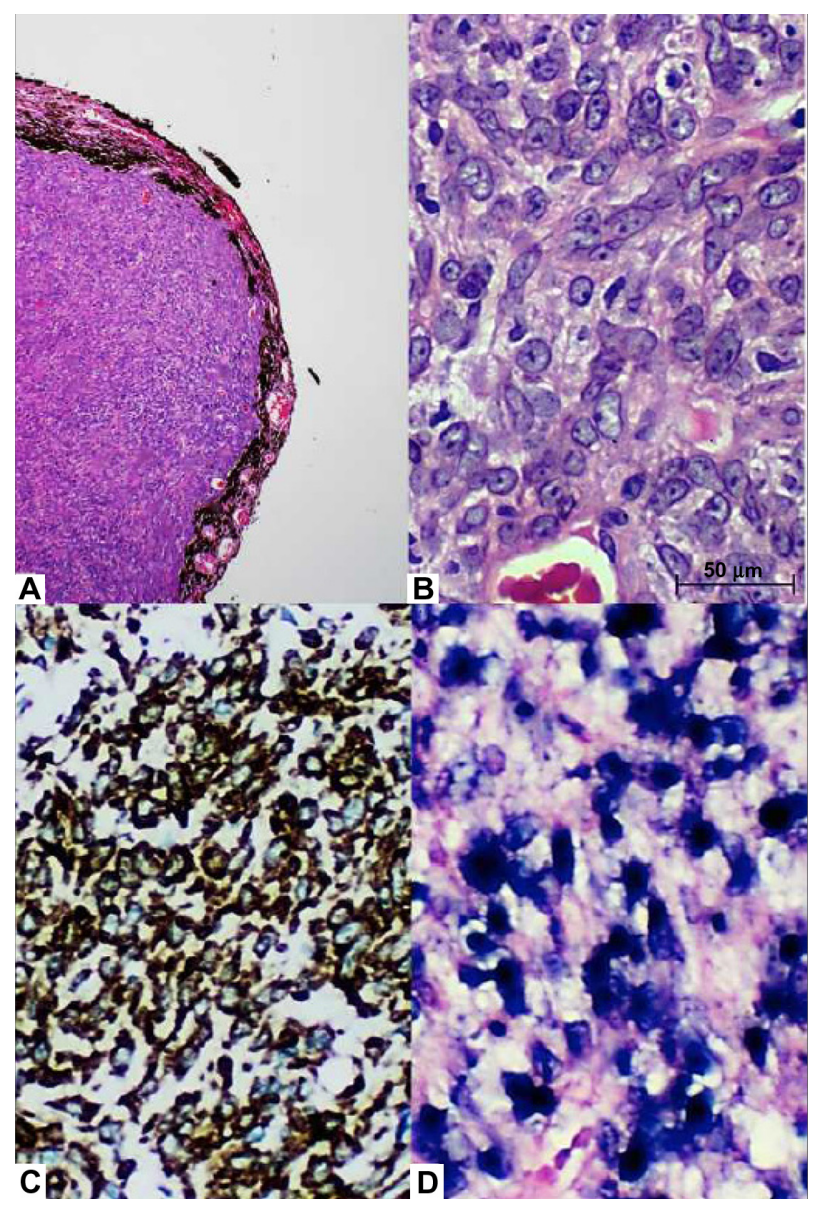

Figure 3 Histopathology and Immunohistochemical stain.

Notes: (A) Histopathology of the surgical specimen showing attached iridic tissue (H\&E $\times 40)$. (B) Tumor cells having plump shape and epithelioid appearance with mildly pleomorphic and vesicular nuclei $(H \& E \times 400)$. (C) Immunohistochemical stain for alpha smooth muscle actin (IHC $\times 100)$. (D) In situ hybridization for EBER shows positive reaction $(E B E R \times 400)$.

Abbreviations: EBER, Epstein-Barr virus-encoded RNA; H\&E, hematoxylin and eosin; IHC, immunohistochemistry. 


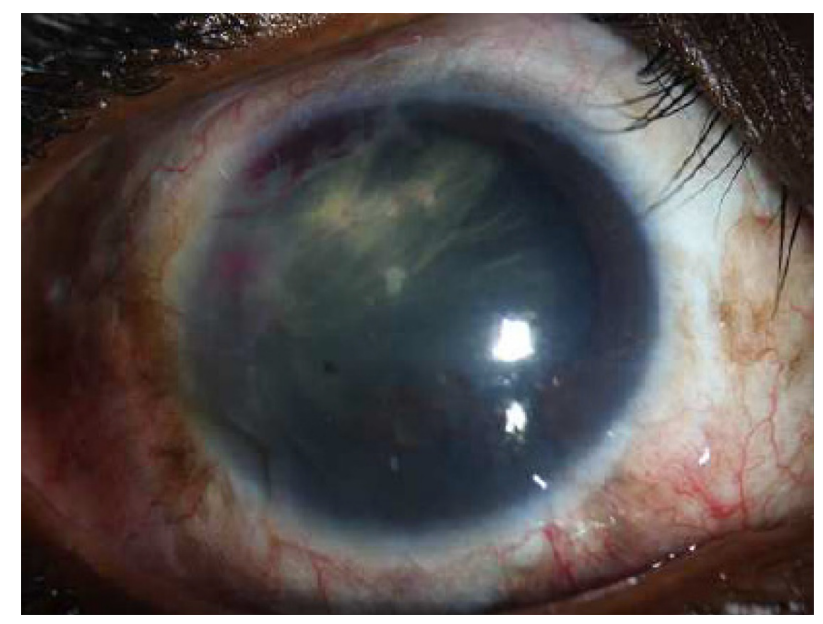

Figure 4 Final slit-lamp biomicroscopy at 8 months revealed the absence of tumor recurrence.

At 14-month follow-up, the patient was free of disease. The visual acuity was 20/25 OD (Figure 4).

This study was approved by the Ramathibodi Hospital, Mahidol University Ethic committee. Written, informed consent was obtained from all subjects and the study adhered to the tenets of the Declaration of Helsinki.

\section{Discussion}

EBV-induced SMTs have been described in AIDS as well as in organ transplantation. ${ }^{3}$ The pathogenesis of this change appears to be related to the viral infection that induces neoplastic transformation of infected smooth muscle cells. However, it is unclear as to how these microorganisms can lead to such tumorigenesis. ${ }^{9}$

Several anatomical locations have been involved by these tumors ${ }^{1,10,11}$ of which the central nervous system is the most common site, followed by the soft tissue. ${ }^{9}$ Of these patients, many of them have multiple organ involvement. ${ }^{9}$

Although several cases of SMTs have been reported in the iris, only seven cases were proven to be associated with an EBV infection. ${ }^{2,412}$ Herein, we present the case of EBV-SMT. The tumor is believed to arise from the dilator and sphincter muscles, which are of neuroectoderm in origin. The unique feature for our case is its dominant epithelioid morphology, different from the typical plump spindle (cigar-shaped) cells that comprise the major part of those described in other reports. This appearance likely represents a histologic variant, similar to its non-EBV related, SMT counterpart.

We prefer to use the term "EBV-associated SMT" for our case rather than EBV-associated leiomyosarcoma as reported by some authors, ${ }^{9}$ since the criteria for distinction between benign and malignant neoplasms for EBV-SMT, so far, have not yet been well established. ${ }^{9}$ In the review article by Purgina et $\mathrm{al}^{9}$ in which 64 published cases of EBV-SMT were analyzed, there was no difference in clinical outcomes between the groups diagnosed with leiomyoma and leiomyosarcoma using the same criteria with the soft tissue counterpart of non-EBV-related SMTs. As such, until when there are generally accepted criteria to separate benign from malignant EBV-related SMTs, the diagnostic term and criteria used for EBV-related SMTs should not be similar to the usual type of non-EBV-associated neoplasms at present.

Histologically, the iris EBV-SMT should be distinguished from amelanotic spindle cell melanoma which can be difficult without the assistance of immunohistochemical studies owing to their overlapped morphologic features. Foss et al reported 24 cases of patients with SMTs all of which turned out to be melanocytic neoplasms when studied with appropriate immunohistochemistry. ${ }^{13}$ In this particular case, most tumor cells were of epithelioid shape, therefore, epithelial tumors and several epithelioid mesenchymal neoplasms were included for differential diagnosis. However, with the history of HIV infection in this patient, EBV-SMT was suspected and immunohistochemistries as well as in situ hybridization for EBV were performed to confirm such diagnosis.

When compared with the classic, non-EBV-related leiomyosarcomas, the histology of EBV-SMT is somewhat different to the former. They hardly achieve the level of atypia noted in the classic leiomyosarcomas, although many display some levels of mitotic activity. ${ }^{14}$ In addition, primitive rounded smooth muscle cell nodules can be identified as a minor part among interlacing fascicles of differentiated cigar-shaped smooth muscle cells in about half of the cases. ${ }^{14}$ Intralesional T-lymphocytes are also a common feature of this entity. ${ }^{14}$

EBV is also implicated in the pathogenesis of a number of hematological and nonhematological neoplasms. ${ }^{15}$ Studied results indicated that the other EBV-related neoplasms, for example, lymphoid neoplasms, were the consequence of a second, independent EBV infection, due to the persistent immunodeficiency of the patient. ${ }^{16}$

Due to the lightly pigmented nature of these tumors, transillumination defects might be difficult to determine tumor extension. ${ }^{7}$ It has been suggested that fluorescein angiography is probably a better tool for achieving this purpose. ${ }^{17}$

In general, EBV-SMT appears to have a variable aggressiveness and clinical outcomes. Compared with conventional, non-EBV-related leiomyosarcoma that often progresses with hematogenous spread and distant metastasis, EBV-SMT tends to have more favorable clinical courses. Patients who develop such lesions have rarely died as a direct consequence of the 
tumors. From one previous report, ${ }^{9}$ tumor-related deaths from EBV-SMT occurred in only 6\%. Surgical resection was the main therapeutic approach in the previously published studies.

For the iris tumors, there are limited data about the natural course of disease since only eight iris EBV-SMTs have been described including this case. Three patients acquired HIV infection since birth. ${ }^{2,4}$ The latter two cases were 10 years and more older than the first case who was a 4-year-old female. ${ }^{2,4}$ The delay in presentation of disease might be explained by more effective antiretroviral regimens against HIV virus. From our last report, ${ }^{4}$ serial slit-lamp photography documented a $100 \%$ enlargement of the tumor dimension within 2 months. Although the iris mass in our patient was much larger than that of the previous reports, it was surprisingly indolent and it minimally disturbed the patient. All patients shared a common feature of a very low CD4 count, which might indicate a tendency of this condition to occur in a severely compromised host. Mean CD4 count was $\sim 60$ cells $/ \mu \mathrm{L}$ from the previous report. ${ }^{9}$

\section{Conclusion}

In conclusion, we present a case of an iris EBV-SMT, which is unique in its epithelioid morphology as a dominant feature. Although relatively rare, this entity should be regarded as one differential diagnosis in HIV-infected patients who have spindle or epithelioid neoplastic lesions for which confirmatory immunohistochemistry and EBV study are necessary.

\section{Acknowledgment}

The authors would like to thank Kirsten Russell for manuscript revision.

\section{Disclosure}

The authors report no conflicts of interest in this work.

\section{References}

1. McClain KL, Leach CT, Jenson HB, et al. Association of Epstein-Barr virus with leiomyosarcomas in children with AIDS. $N$ Engl $J$ Med. 1995;332(1):12-18.
2. Tulvatana W, Pancharoen C, Mekmullica J, et al. Epstein-Barr virus-associated leiomyosarcoma of the iris in a child infected with human immunodeficiency virus. Arch Ophthalmol. 2003;121(10): 1478-1481.

3. Yu L, Aldave AJ, Glasgow BJ. Epstein-Barr virus-associated smooth muscle tumor of the iris in a patient with transplant: a case report and review of the literature. Arch Pathol Lab Med. 2009;133(8): $1238-1241$.

4. Suwan YRD, Teekhasaenee C, Aroonroch R. Epstein-Barr virusassociated iris leiomyosarcoma in an AIDS patient: a case report. J Clin Exp Ophthalmol. 2014;5:342.

5. Okamoto N, Sotani T, Shimo-Oku M, Sashikata T. A case with leiomyoma of iris extirpated with cryosurgery and its pathological findings. Acta Ophthalmol (Copenh). 1982;60(2):183-189.

6. Jellie HG, Gonder JR, Willis NR, Green L, Tokarewicz AC. Leiomyoma of the iris. Can J Ophthalmol. 1989;24(4):169-171.

7. Eide N, Farstad IN, Roger M. A leiomyoma of the iris documented by immunohistochemistry and electron microscopy. Acta Ophthalmol Scand. 1997;75(4):470-473.

8. Tuncer S, Peksayar G, Demiryont M, Gozum N. Long term follow-up of a patient with iris leiomyoma treated with partial lamellar iridocyclectomy. Acta Ophthalmol Scand. 2004;82(1):112-114.

9. Purgina B, Rao UN, Miettinen M, Pantanowitz L. AIDS-related EBVassociated smooth muscle tumors: a review of 64 published cases. Patholog Res Int. 2011;2011:561548.

10. Zevallos-Giampietri EA, Yanes HH, Orrego Puelles J, Barrionuevo C. Primary meningeal Epstein-Barr virus-related leiomyosarcoma in a man infected with human immunodeficiency virus: review of literature, emphasizing the differential diagnosis and pathogenesis. Appl Immunohistochem Mol Morphol. 2004;12(4):387-391.

11. Zetler PJ, Filipenko JD, Bilbey JH, Schmidt N. Primary adrenal leiomyosarcoma in a man with acquired immunodeficiency syndrome (AIDS). Further evidence for an increase in smooth muscle tumors related to Epstein-Barr infection in AIDS. Arch Pathol Lab Med. 1995;119(12):1164-1167.

12. Dugmore WN. 11-year follow up of a case of iris leiomyosarcoma. Br J Ophthalmol. 1972;56(4):366-367.

13. Foss AJ, Pecorella I, Alexander RA, Hungerford JL, Garner A. Are most intraocular "leiomyomas" really melanocytic lesions? Ophthalmology. 1994;101(5):919-924.

14. Goldblum J, Folpe A, Weiss A. Enzinger and Weiss's Soft Tissue Tumors. 6 ed. Philadelphia, PA: Elsevier Saunders; 2014:549-568.

15. Hsu JL, Glaser SL. Epstein-Barr virus-associated malignancies: epidemiologic patterns and etiologic implications. Crit Rev Oncol Hematol. 2000;34(1):27-53.

16. Petrilli G, Lorenzi L, Paracchini R, et al. Epstein-Barr virusassociated adrenal smooth muscle tumors and disseminated diffuse large B-cell lymphoma in a child with common variable immunodeficiency: a case report and review of the literature. Int J Surg Pathol. 2014;22(8):712-721.

17. Sevel D, Tobias B. The value of fluorescein iridography with lleiomyoma of the iris. Am J Ophthalmol. 1972;74(3):475-478.
International Medical Case Reports Journal

\section{Publish your work in this journal}

The International Medical Case Reports Journal is an international, peer-reviewed open-access journal publishing original case reports from all medical specialties. Previously unpublished medical posters are also accepted relating to any area of clinical or preclinical science. Submissions should not normally exceed 2,000 words or

\section{Dovepress}

4 published pages including figures, diagrams and references. The manuscript management system is completely online and includes a very quick and fair peer-review system, which is all easy to use. Visit $\mathrm{http}: / /$ www.dovepress.com/testimonials.php to read real quotes from published authors. 